\title{
Laboreal
}

Volume $11 \mathrm{~N}^{\circ} 1$ | 2015

Modos de vida e trabalho

\section{Encontros sobre o trabalho: reflexões sobre o uso desta ferramenta metodológica em pesquisas em Unidades de Tratamento Intensivo Neonatais}

Encuentros sobre el trabajo: reflexiones sobre el uso de esta herramienta metodológica en investigaciones en Unidades de Cuidados Intensivos en Neonatología

Rencontres sur le travail : réflexions à propos de l'utilisation de cet outil méthodologique dans des recherches en Unités de Soins Intensifs Néonataux Meetings about the work: reflections on the use of this methodological tool in research in Neonatal Intensive Care Units (NICU)

Letícia Pessoa Masson, Luciana Gomes e Jussara Brito

\section{OpenEdition}

\section{Journals}

\section{Edição electrónica}

URL: http://journals.openedition.org/laboreal/4021

DOI: $10.4000 /$ laboreal.4021

ISSN: 1646-5237

\section{Editora}

Universidade do Porto

\section{Refêrencia eletrónica}

Letícia Pessoa Masson, Luciana Gomes e Jussara Brito, « Encontros sobre o trabalho: reflexões sobre o uso desta ferramenta metodológica em pesquisas em Unidades de Tratamento Intensivo Neonatais ", Laboreal [Online], Volume $11 \mathrm{~N}^{0} 1$ | 2015, posto online no dia 01 julho 2015, consultado o 09 outubro 2019. URL : http://journals.openedition.org/laboreal/4021 ; DOI : 10.4000/laboreal.4021

Este documento foi criado de forma automática no dia 9 outubro 2019.

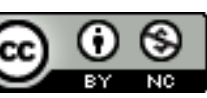

Laboreal está licenciado com uma Licença Creative Commons - Atribuição-NãoComercial 4.0 Internacional. 


\section{Encontros sobre o trabalho: reflexões sobre o uso desta} ferramenta metodológica em pesquisas em Unidades de Tratamento Intensivo Neonatais

Encuentros sobre el trabajo: reflexiones sobre el uso de esta herramienta metodológica en investigaciones en Unidades de Cuidados Intensivos en Neonatología

Rencontres sur le travail : réflexions à propos de l'utilisation de cet outil méthodologique dans des recherches en Unités de Soins Intensifs Néonataux Meetings about the work: reflections on the use of this methodological tool in research in Neonatal Intensive Care Units (NICU)

Letícia Pessoa Masson, Luciana Gomes e Jussara Brito

\section{NOTA DO EDITOR}

http://dx.doi.org/10.15667/laborealxi0115lpm

Manuscrito recebido em: novembro 2014

Aceite após peritagem: abril 2015

\section{Introdução}

1 Este artigo pretende discutir o uso de uma ferramenta metodológica, denominada "Encontros sobre o Trabalho" (EST ${ }^{[1]}$ ), que busca propiciar o debate, a reflexão e o desenvolvimento da atividade de trabalho. Trata-se de uma produção necessariamente 
coletiva, constituindo-se de uma forma de colocar em prática o que a Ergologia (Schwartz, 2000) nomeia por Dispositivo Dinâmico de Três Polos (DD3P). Criado a partir de uma avaliação sobre os limites [2] do conceito de "Comunidade Científica Ampliada (CCA)", tal dispositivo tem a perspectiva de transformar positivamente o trabalho, ressaltando que a necessária interlocução entre os dois polos de saberes relativos ao trabalho humano - os saberes formais, gerados por diversas disciplinas e campos de conhecimento, e os saberes advindos da experiência prática dos trabalhadores - exige um postura ético-epistêmica. Isto significa que a dinâmica gerada pela instauração deste terceiro polo do dispositivo (ético-epistêmico) é o que garante o diálogo respeitoso e produtivo entre os dois polos anteriores, assim como a percepção da riqueza e incultura recíproca, permitindo que ambos se desenvolvam. Assim, em meio a um processo dinâmico, os posicionamentos teóricos dos diferentes campos de conhecimento do primeiro polo devem ser validados a partir da confrontação com os saberes da prática, enquanto ocorre a sistematização reflexiva sobre o patrimônio de saberes-fazer.

2 Nesta perspectiva, os EST devem se configurar como um espaço de circulação dialógica com foco na atividade de trabalho que envolve de forma comum seus participantes (Durrive, 2010). Esse espaço deve contemplar o debate sobre as normas antecedentes do trabalho (prescrições, regulamentações, condições de realização) e o que se caracteriza por renormatizações (o que comporta as mobilizações individuais e coletivas necessárias para a realização da atividade). Durrive (2010) ressalta que, neste espaço, os trabalhadores podem se apropriar de suas experiências e competências de uma nova maneira, convocando saberes formais em processos de validação das descobertas que alimentam incessantemente novas perspectivas para o debate.

O intercâmbio entre os dois primeiros polos do dispositivo - possibilitado de forma privilegiada pelos EST - caminharia para a construção de uma Comunidade Ampliada de Pesquisa e Intervenção (CAPI) ${ }^{[3]}$, propiciando a produção coletiva de saberes inéditos. A partir do "cruzamento de diferentes patrimônios" (Athayde, Zambroni-deSouza \& Brito, 2014), pode-se compreender-transformar ${ }^{[4]}$ a atividade em análise, a vida das pessoas no trabalho.

4 Na perspectiva de que a CAPI engendre também uma comunidade dialógica de pesquisa, deve-se criar "situações novas nas quais os protagonistas são liberados dos constrangimentos inerentes à atividade cotidiana" (França, Di Fanti \& Vieira, 2005, p. 10). Trata-se, assim, de construir situações que possibilitem o diálogo e a "coelaboração" entre os protagonistas da atividade e os profissionais analistas do trabalho com a criação de "novos pontos de vista sobre a ação" (idem, ibidem p.10). Tais pontos de vista estariam ligados à compreensão da construção histórica das normas antecedentes no trabalho e da importância de uma luta coletiva para o estabelecimento de renormatizações frente às suas inadequações à realidade dinâmica da vida.

5 Neste sentido, esta ferramenta metodológica possibilita "recusar antolhos que levam a ver como natural o que na verdade é produção sócio-histórica" (Athayde et al, 2014, p. 146) e dar um novo estatuto aos conhecimentos dos trabalhadores, organizando o encontro de duas expertises de origens diferentes, que exercitam a atenção "ao que muitas vezes se ignora (ou se prefere ignorar)" (ibidem, p. 146). Assim, centrados no mesmo objeto, os operadores refletem sobre suas práticas profissionais, e os pesquisadores intermedeiam o espaço de expressão e desenvolvem e propõem uma inovação metodológica (França et al, 2005, p. 11). 
6 No presente artigo, discutiremos os modos como a ferramenta EST foi experimentada como recurso metodológico em duas pesquisas que seguiram a perspectiva ergológica e buscaram compreender-transformar a relação saúde-trabalho de auxiliares e técnicos de enfermagem em duas diferentes Unidades de Tratamento Intensivo Neonatais (UTIs Neonatais). A aproximação deste campo de estudo se deu a partir de uma experiência de estágio durante a graduação em Psicologia em um hospital municipal do Rio de Janeiro, no qual uma das autoras teve a oportunidade de participar de reuniões realizadas com profissionais que atuavam nesta Unidade e, desta forma, entrar em contato com suas demandas.

7 Acrescentamos que, visando analisar e discutir os resultados das duas pesquisas e seguindo a démarche ergológica, recorremos a diferentes abordagens Clinicas do Trabalho (Lhuilier, 2006) para compor o primeiro polo do DD3P, com destaque para aquelas que privilegiam o ponto de vista da atividade. Elas foram conjugadas ao olhar sociológico, especialmente através dos estudos que tratam das relações de gênero no trabalho. Assim, foram consideradas dimensões distintas do trabalho humano, confrontadas com a experiência prática de auxiliares e técnicos de enfermagem de UTIs Neonatais, através de estratégias cuidadosamente definidas nos próprios campos de pesquisa, como será explicitado a seguir.

\section{Fazendo uso da Ferramenta EST em duas pesquisas em UTIs Neonatais}

\subsection{Encontros sobre o Trabalho com auxiliares de enfermagem de uma Unidade Neonatal ${ }^{[5]}$ em um hospital-maternidade municipal}

8 A relação entre a dimensão relacional da atividade de trabalho e a saúde de auxiliares de enfermagem da Unidade Neonatal de um hospital municipal do Rio de Janeiro foi objeto de análise de uma pesquisa-intervenção desenvolvida no âmbito de um curso de mestrado (Masson, 2007).

9 Conforme explicitado acima, antes do início desta pesquisa tivemos a oportunidade de participar de reuniões com essas profissionais (neste caso todas eram mulheres). Essas reuniões eram coordenadas pela chefe do Serviço de Saúde Mental (psicóloga e supervisora do estágio) e tinham como objetivo funcionar como "grupos de escuta" sobre questões trazidas principalmente pelos trabalhadores de enfermagem da Unidade. Estes grupos funcionavam a partir de uma perspectiva de escuta psicanalítica e tinham a participação da chefia de enfermagem, além de enfermeiros e auxiliares.

10 A realização destas reuniões surgiu a partir da preocupação de uma médica em oferecer - principalmente às auxiliares de enfermagem - cursos de orientação sobre a humanização dos procedimentos feitos com os bebês internados na Unidade Neonatal, com temas como: posicionamento dos bebês na incubadora, exposição à luminosidade $\mathrm{e}$ a ruídos e a prevenção de infecções hospitalares. A ideia de oferecer uma escuta a essas profissionais antes da realização dos cursos se relacionava com uma preocupação em considerar o ponto de vista da realidade prática do trabalho das auxiliares, podendo haver maior espaço para que elas incorporassem novos modos de proceder, provindos de estudos científicos. 
11 As falas das trabalhadoras durante as reuniões chamaram nossa atenção, especialmente no que tange às relações conflituosas e desgastantes decorrentes do contato próximo e corrido com os bebês - em sua maioria prematuros e/ou com graves acometimentos à saúde, sendo atendidos por um número restrito de auxiliares, dentro de uma Unidade de Tratamento Intensivo quase sempre superlotada. As auxiliares foram as que mais apresentaram questões sobre o cotidiano de trabalho na UTI e contaram sobre como faziam para lidar com os embates e as dificuldades de suas atividades, incluída aí a proximidade (corporal e afetiva) com seus pacientes-bebês. A partir daí, e visto que as auxiliares demonstraram valorizar um espaço em que pudessem falar sobre o seu trabalho e apresentavam demanda para tal, fomos despertadas a voltar a esta Unidade (o que ocorreu três anos depois) para aprofundar um diálogo que fora apenas esboçado durante o estágio.

12 Tendo como eixo central o "ponto de vista da atividade" (Schwartz \& Durrive, 2010), os principais referenciais teóricos utilizados na pesquisa foram a concepção de saúde presente na obra de Georges Canguilhem (1990/2011) e a perspectiva ergológica, incorporando aportes teórico-metodológicos de abordagens clínicas do trabalho, como a Ergonomia da Atividade (Guérin, Laville, Danielou, Durafourg \& Kerguelen, 2001), a Psicodinâmica do Trabalho (Dejours, 2008) e a Clínica da Atividade (Clot, 2006). Tais aportes foram articulados às proposições de Philippe Zarifian (2001a) sobre o modelo de competência e a lógica presente na relação de serviço. Consideraram-se, ainda, as contribuições da literatura relativa às Relações Sociais de Sexo (Kergoat, 1989, 1996; Hirata, 2002).

13 A proposta da pesquisa foi de compreender-transformar a atividade de lidar com bebês internados na Unidade Neonatal e seus familiares, considerando as marcas de um trabalho fortemente naturalizado como de menor complexidade e fácil realização (se comparado com o de outros profissionais da "hierarquia hospitalar"), e sua contraposição a um trabalho complexo que envolve, especialmente e cada vez mais, a demanda pela realização de uma atividade de coprodução de um serviço (Zarifian, 2001a) com os familiares dos bebês. Neste sentido, a pesquisa tratou justamente da relação entre a dimensão relacional da atividade de trabalho e a saúde destas trabalhadoras.

14 Assim, nessa primeira experiência em Unidade Neonatal, os Encontros sobre o trabalho foram precedidos por dez visitas à unidade, com três horas de duração cada, nos diferentes turnos de trabalho, o que permitiu o contato com todas as equipes que ali atuavam. Tal etapa foi decisiva para a aproximação inicial ao ambiente de trabalho, às situações de trabalho e às próprias trabalhadoras.

15 Assim, como inserção inicial e espaço para uma análise global do trabalho (Vidal, 2003), as visitas ${ }^{[6]}$ envolveram conversas com as auxiliares ao longo da realização de suas atividades, buscando não interrompê-las (por mais que nossa presença necessariamente gerasse alteração na rotina), mas observar e dialogar com as trabalhadoras no curso da ação, em seu ambiente e horário de trabalho. Ao longo ou logo após as visitas, fazíamos registros dos diálogos e de nossas observações e estes serviram de base para a definição dos temas de debate nos EST, bem como para a incitação ao debate. Além disso, as visitas foram um momento de "convite" às trabalhadoras para o debate em grupo, já que as conversas nesta primeira etapa da pesquisa aconteciam de forma individualizada, com as trabalhadoras presentes na Unidade Neonatal e que se mostravam interessadas e disponíveis ao diálogo. 
16 A partir das sugestões das auxiliares e da concordância de sua chefia, também chegamos à definição do melhor horário para a realização dos EST, situado entre o período do almoço e a administração da dieta das $15 \mathrm{~h}$ aos bebês internados. Foram realizados seis Encontros, com duração de cerca de uma hora, no interior da jornada de trabalho, em dias de semana variados, entre os meses de agosto e outubro de 2006. Os Encontros tiveram a participação de nove auxiliares de um dos plantões diurnos (que, ao todo, possuía vinte auxiliares) que se revezaram entre as reuniões, gerando grupos compostos por quatro participantes, em média. Diferentemente das visitas, que foram realizadas em todas as equipes de plantão da Unidade, os Encontros ocorreram apenas com uma delas: a que teve um número maior de trabalhadoras demonstrando interesse em participar ${ }^{[]]}$.

17 Os diálogos travados nos Encontros foram registrados por meio de gravação em áudio, além de anotações que compunham um diário de campo. Os debates foram transcritos com a preocupação de abarcar sua dinâmica linguageira mais ampla, ou seja, buscando dar atenção aos períodos de silêncio, às diferentes entonações, aos risos, às falas embargadas, às interrupções e sobreposições, etc.

18 A pesquisa contou, em todas as suas etapas, com uma profissional psicóloga, responsável pela dissertação de mestrado, e com uma estudante de psicologia. A primeira foi a principal interlocutora das conversas durante as visitas e mediadora dos debates. A segunda ficou como a primeira responsável pelos registros.

19 Houve ainda a discussão sistemática sobre os Encontros por uma equipe ad hoc, composta por dois pesquisadores experientes na área das perspectivas clínicas do trabalho (orientadora e coorientador da dissertação). Eram realizadas reuniões entre um e outro EST, que visavam tanto à análise do que havia ocorrido no Encontro anterior, como à preparação do seguinte e demais passos da pesquisa.

20 Ao longo dos Encontros, apresentamos às trabalhadoras alguns conceitos relacionados à perspectiva ergológica (Schwartz \& Durrive, 2010), com o intuito de oferecer elementos de discussão sobre temas relacionados às atividades concretas destas trabalhadoras na Unidade Neonatal. Os temas destes EST foram, respectivamente: formação profissional das auxiliares de enfermagem; as relações entre as diferentes equipes de trabalho ou a construção de "entidades coletivas relativamente pertinentes" no trabalho; organização do trabalho (formal e informal); e condições de trabalho.

21 Os temas não foram discutidos de forma estanque e operaram como "geradores" (Freire, 1970/2011) do debate, sendo oriundos tanto das primeiras reflexões que inspiraram o estudo, quanto das questões suscitadas e análises realizadas a partir das visitas e dos documentos pesquisados.

Os Encontros tiveram a participação variada das auxiliares, mas como as discussões eram centradas, primordialmente, em questões que perpassavam aquele coletivo de trabalho (e não em problemas individuais), este fato não representou um obstáculo ao andamento da pesquisa. Cabe mencionar que a decisão sobre quem iria ao grupo foi gerida pelas próprias auxiliares participantes que, muitas vezes, se mostravam preocupadas com a participação das colegas que haviam permanecido na assistência.

23 Durante o Pré-encontro, propusemos uma discussão inicial acerca dos temas propostos, procurando identificar se eram coerentes para elas, e buscamos, também, ouvir outras ideias e sugestões, tanto sobre os temas a serem debatidos, como sobre o modo de funcionamento dos EST. Mas já neste momento as trabalhadoras começaram a 
comentar propriamente os temas sugeridos, em vez de se posicionar sobre se estes seriam ou não interessantes de serem debatidos. Uma das auxiliares iniciou a discussão sobre formação, relatando sua trajetória profissional. A partir daí, as demais também fizeram comentários sobre este tema, especialmente sobre como viam o elemento "experiência" para a realização do trabalho no setor.

Essa trabalhadora é a auxiliar que tinha mais tempo na Unidade entre as que estavam neste Encontro, e uma das mais antigas entre todas as auxiliares com quem conversamos. Foi também a primeira a falar no grupo, já de início trazendo a questão do "tempo de casa", que é algo que, sem dúvida, lhe dá orgulho e um tanto de autoridade, pelo menos entre as suas colegas. Ela se aprofundou neste tema contando sobre sua "estreia" na Unidade de maneira entusiasmada, mesmo que tenhamos explicitado que o objetivo do Pré-Encontro era apresentar o modo de funcionamento dos EST e os temas que viriam a ser discutidos.

Assim, já no Pré-encontro, a temática da "formação profissional" foi "apropriada" por uma das participantes como algo que remeteria não apenas à ideia de "tempo de casa" como tempo cronológico de experiência, mas também à diversidade de experiências $\mathrm{e}$ enfrentamentos cotidianos vividos por cada uma delas, que serviriam de elementos para atuação na Unidade Neonatal com competência e "desenvoltura".

Este seria um exemplo de como a dinâmica dos Encontros pode mostrar-se surpreendente, assim como pode ser um espaço propício à "reapropriação" de conceitos e temas científicos pelo saber-fazer dos protagonistas da atividade.

o Pré-encontro também foi um espaço utilizado pelas trabalhadoras para expressar características daquele coletivo, especialmente as mais "típicas". Alguns exemplos disso são: a força coletiva daquele grupo, apesar da fragilidade e da invisibilidade de seu trabalho frente ao dos demais profissionais da Unidade; certa "bravura" para brigar por melhores condições de trabalho e para enfrentar as dificuldades de uma formação muito prática e baseada em saberes considerados naturais para as mulheres e com pouco amparo formal, resumindo-se, na época, a um treinamento feito "de auxiliar para auxiliar" durante a própria realização do trabalho. Este Encontro também foi muito rico no que tange a falas e trocas que se esboçavam ali na CAPI, na medida em que se caracterizava como um espaço em relação ao qual as trabalhadoras mostravamse bastante carentes.

Pudemos notar também que a reapropriação e o desenvolvimento proporcionados pelo espaço reflexivo dos EST não ocorriam necessariamente com a utilização de expressões já habituais entre as participantes, mas também com o uso de palavras pouco usuais no contexto daquele coletivo e que foram sendo descobertas ao longo da troca entre elas e com os profissionais de pesquisa. Exemplo disso foi a chegada à palavra "desenvoltura" por um grupo de auxiliares de enfermagem que debatia sobre a formação - fortemente prática - para realizarem o trabalho em Unidade Neonatal. Depois do EST em que despontou a expressão, esta foi levada com destaque pelas pesquisadoras para a continuidade da discussão sobre o tema, sendo incorporada pelo conjunto das trabalhadoras, viabilizando colocar em palavras algo difícil de ser expresso: a competência construída ao longo dos anos e da formação formal/informal das auxiliares.

29 Com relação a esta observação, Dejours (2008) aponta justamente um movimento que pode ser bastante fecundo, que é "quando os trabalhadores passam a formular para o pesquisador coisas que nem eles próprios tinham claro antes de formulá-las 
discursivamente para uma pessoa de fora" (p.123). Neste sentido, chama-se a atenção para expressões criadas no espaço de discussão coletiva dos EST e encarnadas pelos trabalhadores a partir do esforço de sistematização e visibilização promovido pela "descoberta" de novas palavras para traduzir e reconstruir o vivido no trabalho.

Entendemos também que, para que este tipo de reformulação e reapropriação possam de fato ocorrer, é necessário que os EST se constituam como um espaço de construção do polo ético-epistêmico, que pressupõe a instauração de um clima de confiança e de respeito entre diferentes tipos de saberes e conhecimentos, além da vontade comum de criar algo novo a respeito da atividade do coletivo envolvido na pesquisa-intervenção.

Durante os Encontros I, II, III e IV, além da apresentação de conceitos relacionados aos temas propostos, utilizamos falas das próprias trabalhadoras - enunciadas durante as visitas e durante os Encontros que os antecederam - como mobilizadores da discussão sobre sua atividade. Estas falas suscitaram as mais interessantes e variadas reações, confirmando seu papel como instrumento de incentivo aos comentários, explorando a ação da atividade linguageira sobre a atividade de trabalho. Deste modo, uma espécie de confrontação no diálogo, possibilitada pela leitura de enunciados remetidos a elas próprias, parecia, muitas vezes, fazê-las repensarem, reelaborarem a própria relação com (ou opinião sobre) o seu trabalho.

$\mathrm{Na}$ tentativa de estabelecer a circulação, a relação entre os Encontros, e procurando dar continuidade e encaminhamento às discussões iniciadas nos anteriores, resgatávamos questões antes debatidas para reapresentá-las às participantes. Assim, cada pré-análise realizada pela equipe de pesquisa entre um EST e outro era sinteticamente apresentada às trabalhadoras, buscando uma ligação com o tema do EST atual. Esta proposta continha a ideia de que a (in)validação das auxiliares sobre nossas análises pudesse ocorrer ao longo dos próprios Encontros, procurando favorecer o desenvolvimento das questões e da maneira como estas eram colocadas em palavras.

O último Encontro foi dividido em dois momentos, com dinâmicas diferentes, porém complementares. Inicialmente, foi proposto às trabalhadoras um debate sobre as questões já discutidas em Encontros anteriores, com o objetivo de gerar proposições sobre como elas gostariam que suas situações de trabalho se modificassem. Este debate foi acompanhado por anotações feitas durante o Encontro, sinalizando as propostas das participantes em uma folha de papel pardo com o objetivo de facilitar a discussão dos encaminhamentos sugeridos.

Em seguida, solicitamos que elas registrassem em outra folha que continha o desenho da planta física da Unidade Neonatal (através de colagens e desenhos), o modo como gostariam que fosse o funcionamento da Unidade e - de forma ao mesmo tempo simbólica e gráfica - o seu próprio trabalho. Este momento possibilitou ainda a discussão de novas questões e o reposicionamento a respeito de outras que já haviam sido anteriormente debatidas.

Por fim, podemos afirmar que os Encontros se mostraram espaços propícios para trazer para o debate aspectos da atividade que as próprias trabalhadoras muitas vezes pareciam não se dar conta, permitindo, a partir da coordenação das pesquisadoras, certa elaboração (no sentido de desenvolvimento e sistematização) dos conteúdos 
emergentes. E, como resultados desta pesquisa-intervenção, destacamos aqueles em que os EST parecem ter sido decisivos para a sua formulação:

- A exposição e a troca de opiniões e valores sobre aspectos pouco visíveis da atividade indicaram um "pano de fundo" comum, ou seja, um cenário compreensível e compartilhável por todas, o que se interpretou como uma característica da construção entre elas de um gênero profissional (Clot, 2006) próprio.

- A questão das relações sociais de sexo (Kergoat, 1996) apareceu com destaque nos EST. Por um lado, a marca feminina da profissão e as naturalizações sociais sobre o que seria cuidar e, especialmente, cuidar de bebês, foi um elemento que prevaleceu e foi questionado pelas trabalhadoras com relação à não valorização de uma formação/qualificação profissional para desenvolverem suas atividades. Por outro, diversos preconceitos de gênero apareceram quando as trabalhadoras se referiam às mães dos pacientes internados, especialmente sobre a presunção de que estas teriam que se comportar invariavelmente de acordo com um ideal do que deveria ser uma mãe. A respeito destas questões, notou-se também um interessante cruzamento com o enfoque do gênero profissional acima citado, a partir de uma forte necessidade de diferenciação entre dois diferentes gêneros de atividade: a profissionalizada (porém carente de qualificação e reconhecimento!) das auxiliares; e a das mães dos bebês as quais, no mesmo espaço, apresentavam-se coproduzindo o serviço de cuidado da saúde de seus filhos de forma não técnica e pouco ou nada sistematizada;

- A emergência - em um ambiente favorável à sua valorização - dos saberes-fazer e competências práticas e da dimensão fortemente relacional do seu trabalho, pouco ou nada (re)conhecidos socialmente, porém fundamentais para a realização de suas atividades. Neste sentido, buscou-se não somente dar-lhes visibilidade, mas entender sua transmissão e seu uso no trabalho na Unidade Neonatal, fazendo-os circular entre elas, a partir de relatos sobre as diversas épocas vividas na unidade pelas diferentes gerações de auxiliares, bem como também sobre suas experiências de vida e trabalho fora dali;

- A dificuldade de acesso à "qualificação formal" tornou-se visível entre as trabalhadoras, revelando fragilidades socioeconômicas que enraízam percursos profissionais não legitimados, marcados por certa ideia de incompletude associada à profissão de enfermagem, que lhes serviria de referência.

36 Tais análises foram sistematizadas no formato de uma dissertação de mestrado e apresentadas às trabalhadoras daquele coletivo em três novos encontros ${ }^{[8]}$ ocorridos cerca de um ano depois da pesquisa, com o objetivo de realizar discussões sistematizadas visando a validação das análises produzidas. Estas discussões foram realizadas contando com a construção de um material impresso ${ }^{[9]}$ distribuído às auxiliares, que continha resultados da pesquisa e questões para o debate, divididos nos seguintes temas: "Os atores presentes nas cenas de trabalho na UTI Neonatal"; "O cenário de atuação das auxiliares: seus recursos e suas deficiências"; e "A necessária atuação em conjunto para a conquista do cuidado".

\subsection{Encontros sobre o trabalho com técnicos e técnicas de enfermagem em uma UTI Neonatal de um hospital escola federal}

A pesquisa-intervenção que foi desenvolvida durante um curso de doutorado em Saúde Pública (Gomes, 2011) buscou compreender as articulações entre saúde e trabalho das técnicas e dos técnicos de enfermagem que atuam em uma UTI Neonatal de um hospital 
escola de grande porte de nível federal, na cidade do Rio de Janeiro, levando em consideração as especificidades da relação de serviço.

Para tanto, também operou com diferentes disciplinas que fazem uso do conceito de atividade e que consideram a complexidade, a dinâmica e a variabilidade das situações de trabalho, assim como a mobilização dos trabalhadores, sendo a pesquisa embasada na Ergologia e nas contribuições de abordagens clínicas do trabalho, como a Ergonomia da Atividade e a Psicodinâmica do Trabalho. Estudos sobre a relaçăo entre a saúde e as atividades de serviço, como os de François Hubault (2009), a respeito da dialética saúdeeficácia relacionada aos recursos disponíveis para agir, e os de Christian du Tertre (2005), sobre a intensidade do trabalho e a saúde nas atividades imateriais e relacionais, também foram contribuições fundamentais. Além disso, tal qual a pesquisa anterior, considerou a lógica de serviço, proposta por Zarifian (2001b, 2001c).

Quanto a seu percurso, este envolveu as seguintes etapas: visitas à Unidade Neonatal, onde foram realizadas observações globais e livres, além de conversas (inclusive enquanto executavam suas atividades) com as técnicas e os técnicos de enfermagem e com a chefia de enfermagem sobre a sua atividade; levantamento e análise de documentos relativos às normas antecedentes e à prescrição do trabalho; aplicação do Inquérito Saúde e Trabalho em Atividades de Serviço (Insats ${ }^{[10]}$ ); organização e cruzamento dos dados encontrados nas visitas e na aplicação do Insats ${ }^{[11]}$ e realização de Encontros sobre o Trabalho.

40 Primeiramente, foi feito contato com a coordenação da Unidade Neonatal e a chefia de enfermagem para dar início ao trabalho de campo. A jornada de trabalho dos técnicos caracterizava-se por turnos de 24 horas trabalhadas por 120 horas de descanso. A pedido dos técnicos e da chefia, as visitas ocorreram no início da tarde, por ser considerado um período mais tranquilo para a enfermagem, uma vez que na parte da manhã diversos profissionais realizavam procedimentos no local. Foram feitas visitas em todas as escalas, em um total de seis, com duração que variava de uma hora a três horas e meia, dependendo de como estava a UTI Neonatal. Inicialmente, apresentou-se a pesquisa aos técnicos e técnicas que atuavam na Unidade e todos foram convidados a participar. Daí por diante foram efetuadas as observações e as conversas. Durante, ou logo após as visitas, os dados produzidos e nossas impressões e percepções eram registrados em diário de campo. Essa etapa foi conduzida entre junho e julho de 2010.

41 Em relação ao Insats, o seu uso proporcionou o detalhamento de dados sobre as condições de trabalho e a saúde dos técnicos de enfermagem devido à forma como esse instrumento foi construído e também por ser voltado às atividades de serviço. Contribuiu também para que os trabalhadores refletissem sobre essa relação, tornando visível uma série de aspectos que não haviam surgido nas outras etapas da pesquisa. Por exemplo, embora os técnicos falassem com muito orgulho das boas instalações de que dispunham (sobretudo porque comparavam com outros lugares em que trabalhavam), ao se depararem no Insats com um item que questiona a adequação dos vestiários e dos banheiros no local de trabalho, apenas um deles respondeu positivamente. Além disso, enquanto estavam preenchendo o instrumento, paravam para discutir determinadas questões com os demais, o que proporcionou uma reflexão coletiva sobre esse e outros assuntos. Vale destacar que apesar desse questionário ser autopreenchido, sua aplicação foi realizada em pequenos grupos, favorecendo as discussões que emergiam. Constatamos, assim, que esse inquérito, além de conduzir o trabalhador a pensar sobre os efeitos das condições em que está trabalhando (Barros- 
Duarte, Cunha, \& Lacomblez, 2007), estimulou o coletivo a conversar espontaneamente sobre o seu trabalho, a vida e a saúde desde a sua aplicação.

42 A combinação de diferentes ferramentas metodológicas produziu um amplo conjunto de informações que revelou múltiplos aspectos das atividades de trabalho dos técnicos e sua relação com a saúde. Com as visitas, produziram-se dados para a pesquisa através da aproximação com os técnicos e técnicas de enfermagem, das suas atividades de trabalho e do funcionamento cotidiano da Unidade, incluindo outros profissionais ali atuantes. Elas possibilitaram conhecer os aspectos mais gerais e observáveis do trabalho destes profissionais. Nesta etapa, buscou-se também manter um olhar atento às especificidades da relação de serviço. $\mathrm{Na}$ análise documental, foram reunidas informações sobre as normas antecedentes e a prescrição do trabalho, a fim de conhecermos melhor o enquadre formal do trabalho nesta Unidade. E através do Insats foram gerados dados sobre a relação entre saúde e trabalho, com ênfase em particularidades das atividades de serviço, como aspectos relacionais e comunicacionais.

A forma como foram conduzidas as etapas descritas acima contribuiu para o estabelecimento de uma relação de confiança entre a pesquisadora e os sujeitos e, em certa medida, para sua formação sobre a relação entre saúde e trabalho. Isto se revelou essencial para o desenvolvimento dos EST, uma vez que representaram os primeiros passos na construção de uma Comunidade Ampliada de Pesquisa e Intervenção.

o cruzamento dos dados gerados nas primeiras etapas da pesquisa com aqueles produzidos pelo Insats permitiu a confirmação de alguns resultados, mas também revelou contradições (Barros-Duarte et al., 2007) e muitos pontos a serem mais bem compreendidos. Assim, a análise desses materiais, a partir das questões iniciais da pesquisa, serviu para orientar os conteúdos que foram abordados nos EST.

Desta forma, para melhor conhecer os desafios que são colocados pelas especificidades da relação de serviço, os materiais foram organizados tendo como referência os seguintes temas:

- Transformações no trabalho referentes ao novo olhar sobre o bebê e ao seu atendimento, às mudanças nos cuidados, às exigências de novas competências aos profissionais, novas atribuições e à introdução das inovações tecnológicas;

- Características da relação/interação dos técnicos com o bebê, a mãe, os colegas e demais profissionais;

- Os vários planos das condições de trabalho (Hubault, 2009): a organização, a avaliação, a gestão e os recursos individuais e coletivos que os trabalhadores e trabalhadoras têm disponíveis para agir.

As visitas e a aplicação do Insats foram organizadas de forma a contemplar todas as equipes de técnicas e técnicos de enfermagem que atuavam na UTI Neonatal. Já para a realização dos Encontros, entendendo que essa ferramenta demanda um envolvimento maior e uma mobilização dos sujeitos no grupo, optamos por trabalhar com uma única equipe, escolhendo aquela que primeiramente demonstrou interesse em participar desta etapa.

47 Foram realizados três Encontros em diferentes espaços dentro da Unidade Neonatal durante a jornada de trabalho, em horários pré-acordados com os técnicos e a chefia de enfermagem - sendo dois dos Encontros com foco na mesma temática, conforme será descrito abaixo. Além da pesquisadora, participaram de três a quatro técnicos, do total 
de seis que atuavam no plantão. Um dos Encontros contou com a participação de uma doutoranda que é chefe de enfermagem da Unidade neotal de outro hospital, que, como uma integrante da equipe de pesquisa, contribuiu para estimular o diálogo com as técnicas e técnicos. A duração dos Encontros variou entre uma hora e uma hora e meia, sendo gravados e posteriormente transcritos. Esses materiais foram complementados com anotações em diário de campo, que continham impressões e percepções da pesquisadora. Os EST aconteceram entre dezembro de 2010 e janeiro de 2011.

48 A fim de estimular a comunicação e a circulação entre os saberes nos EST, os conteúdos foram organizados em formato de slides e apresentados através de um projetor. Em muitos momentos - assim como na experiência anterior - foram expostas falas ou termos usados pelas técnicas e técnicos em outras etapas para evocar algum aspecto ou ilustrar alguma situação e com isso ajudar a provocar o debate e a confrontação com o vivido. Ainda para estimular a fala dos técnicos durante o EST, buscou-se em alguns slides, após apresentar um determinado tema teórico, inserir perguntas questionadoras, de forma que ajudassem a conduzir os trabalhadores a pensar como esse tema se articula à sua realidade. Por exemplo: ao apresentar a proposição de Tertre (2005) sobre as arbitragens que o trabalhador é levado a realizar em tempo real na atividade de serviço (com uma linguagem simples e já ajustada à realidade da UTI Neonatal), ao final foi colocado o seguinte questionamento: "Como você vivencia isso no seu dia a dia?".

49 Nos dois primeiros Encontros foram apresentadas, sinteticamente, as análises preliminares dos resultados obtidos nas outras etapas, a respeito da caracterização do trabalho na UTI Neonatal, das transformações ocorridas no trabalho e nos cuidados e de aspectos da relação direta entre os técnicos, as chefias, os demais profissionais, as mães e os bebês.

50 Esses Encontros tiveram como tema "A dimensão imaterial e relacional da atividade da/o técnica/o de enfermagem na UTI Neonatal ", tendo se desenvolvido em dois momentos diferentes, no mesmo dia. Isso se deu porque no dia previsto para a realização do Encontro I, havia bebês com quadros muito graves internados e a chefia de enfermagem só pôde liberar três técnicos, entre os menos experientes da equipe. Aqueles que não participaram - que eram justamente os que vinham acompanhando de forma mais ativa o desenrolar da pesquisa - solicitaram outro Encontro, no mesmo dia, até porque as equipes seriam reorganizadas nos dias seguintes (o que poderia dificultar a presença deles em um próximo Encontro).

51 Inicialmente, as pessoas que participaram do primeiro momento apenas concordavam com o que estava sendo apresentado ou, no máximo, faziam comentários breves. Ao longo do Encontro é que começaram a interagir mais, trazendo suas experiências e discutindo aspectos de suas atividades. Há que se salientar que esse EST foi realizado na Sala de Atividades Mãe-Canguru, da Unidade Neonatal, e que nesse espaço havia uma médica fazendo anotações nos prontuários e duas mães terminando a colação na mesa ao lado. Além disso, uma enfermeira entrava na sala com certa frequência para falar com a médica. Apesar de terem permanecido em silêncio, suspeitamos que a presença destas pessoas os tenha deixado pouco à vontade.

52 Já no segundo momento, em que estiveram presentes técnicas de enfermagem com maior tempo de experiência naquela UTI Neonatal, bastou explicar a dinâmica dos EST e apresentar o tema no slide para que começassem a falar. Além de discutirem os assuntos em foco, elas puxavam temas complementares. 
53 Nesse Encontro, entre outras questões, os técnicos foram revelando como o patrimônio de valores comuns construídos por esse coletivo (Schwartz, 2010b) norteava suas ações. Por exemplo, chamavam os bebês de "filhos", assumindo uma postura de comprometimento com o cuidado de todos os bebês e não apenas daqueles pelos quais estavam formalmente responsáveis.

O tema do Encontro II foi "Relação de serviço e os desafios à saúde". Ocorreu dentro da UTI Neonatal, o que possibilitou a presença de quatro técnicos, embora houvesse muitos bebês internados. Entretanto, a participação de uma técnica foi flutuante, na medida em que ela precisou se afastar algumas vezes para realizar procedimentos em um bebê.

Nesse Encontro foram apresentados pressupostos teóricos sobre a relação de serviço e os desafios colocados à saúde, articulados à realidade por eles vivenciada. Antes de iniciarmos propriamente esse EST, os técnicos comentaram que após os primeiros Encontros, eles continuaram conversando entre si e com outros colegas a respeito dos assuntos trazidos e as questões que surgiram.

Dos quatro técnicos presentes, três haviam participado dos Encontros anteriores, o que, a nosso ver, contribuiu para seu bom desenvolvimento no que tange a seu caráter formativo. Os participantes expuseram as dramáticas do uso de si (Schwartz, 2010a) vivenciadas em algumas situações de trabalho e, muitas vezes, a fala de um era complementada pelos outros, alimentando a cadeia dialógica e confirmando a sinergia alcançada por esse coletivo.

Constatou-se que os EST, seguindo a perspectiva ergológica, contribuíram na construção e no desenvolvimento do ponto de vista da atividade junto com as trabalhadoras e os trabalhadores, ampliando a comunidade de pesquisa e intervenção. Os Encontros também possibilitaram, em especial, o alcance ou o aprofundamento dos seguintes resultados e conclusões:

- As posturas adotadas pelos técnicos na relação com as mães, em que procuram compreender a situação de sofrimento em que estas se encontram, respeitando seus medos, sua ansiedade, mostram o quanto a dimensão relacional acaba norteando algumas arbitragens em suas atividades;

- As arbitragens e as mobilizações do corpo-si (Schwartz, 2010a) que se efetivam na relação entre os técnicos e os bebês e familiares evidenciam-se de forma especialmente marcante devido à intensidade da experiência de lidar com situações limítrofes, tanto no que se refere ao quadro de fragilidade da saúde dos bebês, quanto do estado emocional dos pais frente a essa situação;

- A construção de um patrimônio de valores comuns e regras de bem viver entre as técnicas e os técnicos se revelou essencial para a formação de um coletivo de trabalho e para a constituição de entidades coletivas relativamente pertinentes (Schwartz, 2010b), onde através de elementos de cooperação e solidariedade se apoiam, bem como buscam fortalecer o seu ofício e o seu coletivo;

- Deparamo-nos com um quadro de adoecimentos e sintomas vagos e difusos que é indicativo do esgotamento desses trabalhadores. Todavia, destacou-se o caráter desafiante que o trabalho na UTI Neonatal apresenta, onde o fato de ser colocado à prova é motivador para os técnicos em suas atividades, o que evita um rumo patogênico (Dejours, 1986). Embora o sofrimento esteja ali presente, a disposição para lutar pela saúde ainda parece prevalecer. 


\section{Considerações sobre as duas experiências de pesquisa} estavam articuladas com os objetivos das pesquisas e temas relacionados às atividades concretas dos trabalhadores na Unidade Neonatal. Assim, os Encontros eram iniciados com esclarecimentos sobre a proposta metodológica, seus objetivos e sua dinâmica. Nosso principal desafio como animadoras dos EST era estimular os participantes a falarem sobre a sua atividade, de forma que compreendessem, como propõe Durrive, "que a atividade nunca é banal, que forçosamente ela tem algo a dizer, porque a vida não para" (2010, p. 314). acontece de forma imediata, tampouco ao mesmo tempo para todos os participantes. Trata-se de um processo de formação e de construção e fortalecimento de recursos coletivos. Felizmente, pudemos observar que à medida que os trabalhadores foram se apropriando do olhar ergológico e fortalecendo seus laços - ao compartilharem seus pontos de vista -, contribuíam para que os demais (que estavam mais distantes das discussões) também incorporassem tal visão.

64 relacionados às situações concretas vivenciadas pelos auxiliares e técnicos de 
enfermagem nas Unidades Neonatais e também de utilizarmos suas próprias falas para ilustrar ou colocar questões, favoreceu a aproximação e a coanálise do que era colocado em discussão.

Apesar de cada situação de trabalho ter aspectos que lhes são singulares, podemos identificar também algumas similaridades quando comparamos o mesmo tipo de unidade de saúde, como no caso das duas pesquisas:

- A Unidade Neonatal é um tipo de unidade hospitalar com alta complexidade tecnológica onde atuam diversos profissionais, a maioria de enfermagem e medicina. Trata-se de um ambiente fechado, com acesso restrito e controlado. Os profissionais de enfermagem que lá trabalham, sobretudo técnicos e auxiliares de enfermagem, não costumam circular pelas outras unidades do hospital. Isso ficou evidente também durante os EST, pois todos foram realizados dentro ou próximo (numa sala externa, no mesmo andar) das duas unidades estudadas, sendo alguns em espaços que estavam momentaneamente desativados e outros dentro do mesmo ambiente em que se encontravam bebês com um quadro mais estável.

- Uma das causas de aumento da intensidade do trabalho para os técnicos e auxiliares de enfermagem pode estar associada ao número de bebês por profissional, mas também ao quadro de saúde de cada bebê. Nesse sentido, as idas ao campo, por mais que fossem combinadas com os trabalhadores e com a chefia de enfermagem e marcadas com antecedência, dependiam sempre de como estava a situação da Unidade Neonatal naquele momento. Por esse motivo, na primeira experiência, houve necessidade de remarcar as idas algumas vezes, através de contatos telefônicos realizados no próprio dia agendado para o EST antes de seguirmos para o hospital. Já na segunda experiência, foi necessário, algumas vezes, reduzir o tempo no campo.

- Os EST ocorreram durante o horário de trabalho, sempre apenas com uma parte do grupo que estava de plantão, já que a outra permanecia assumindo o cuidado dos bebês. Essa cooperação entre eles foi essencial para o desenvolvimento das pesquisas. Contudo, os próprios participantes mantinham-se, na medida do possível (ou seja, quando os EST ocorriam dentro do ambiente da Unidade Neonatal), também atentos a toda movimentação dentro da Unidade, sobretudo, aos bebês de quem estavam cuidando.

- Estimulávamos que fizessem um rodízio entre si para irem a Encontros diferentes, já que não era possível a participação de todos ao mesmo tempo. Isso acabou ocorrendo, apesar de ter havido a predominância da participação de alguns trabalhadores. Assim, de um EST para outro, houve sempre certa rotatividade dos participantes, que também ocorria em função do quadro de saúde dos bebês de quem cada um cuidava no dia. Além disso, a rotatividade também era influenciada pela troca do dia de plantão, algo que comumente ocorre entre esses profissionais, uma vez que precisam ajustar suas escalas de trabalho com as de outros empregos que possuem. Se por um lado, tal descontinuidade na participação pode ter afetado o aprofundamento do diálogo, por outro, teve um caráter multiplicador e assegurou que um número maior de profissionais participasse dos EST.

66 As discussões tinham um tempo para se adensarem, exigindo um esforço das coordenadoras dos EST em construir espaços propícios ao debate produtivo - em que as trabalhadoras ficassem à vontade para se colocar e todas pudessem participar efetivamente (tentando garantir esse espaço às mais tímidas). Este "esforço" remeteria também à importância de se ultrapassar queixas e se pensar encaminhamentos para as discussões, propostas e construção coletiva de caminhos possíveis.

67 Entendemos que adequações ao método utilizado, em maior ou menor grau, sempre serão necessárias no confronto com o real. Nas experiências relatadas aqui, por um 
lado, identificamos dificuldades com relação à continuidade dos Encontros de forma autônoma após as pesquisas-intervenções realizadas e ao protagonismo das trabalhadoras em alcançar as mudanças necessárias. Houve dificuldades, também, em relação a uma maior participação e empenho de outras hierarquias e categorias profissionais na pesquisa. Por outro lado, os Encontros representaram o que se tornou possível realizar diante das condições e do contexto com os quais nos deparamos, além, é claro, de nossas próprias limitações e "variabilidades" enquanto profissionais de pesquisa em formação e com equipes reduzidas.

A partir, então, de uma análise sobre o que seria comum às duas experiências, constatamos que esse dispositivo grupal apresenta um grande potencial para a transformação positiva no pensar-agir dos protagonistas dos dois polos e no meio do trabalho (Athayde et al, 2014). Assim, ressaltamos não apenas as transformações potencializadas no trabalho dos participantes (e de seus coletivos, não necessariamente diretamente participantes), mas também as contribuições inegáveis para a nossa formação (contínua) como pesquisadoras e para o próprio desenvolvimento dos conhecimentos mais estabilizados e científicos sobre a relação trabalho-saúde, a partir da troca e do contato direto com situações concretas de trabalho.

Nas experiências relatadas, os EST (atrelados às demais aproximações, como as visitas e conversas com as trabalhadoras e suas chefias, além do uso do Insats) possibilitaram a emergência de resultados e análises construídas a partir de um frutífero cruzamento de olhares, especialmente no tocante à questão da invisibilidade da dimensão relacional da atividade e da saúde dos trabalhadores em questão.

\section{4. À guisa de conclusão: desafios e aprendizagens em três tempos}

As experiências acima relatadas, articuladas às abordagens teóricas das clínicas do trabalho, possibilitam uma reflexão sobre a operacionalização dos EST que, a nosso ver, pode ser resumida em torno dos três seguintes pontos:

\subsection{Sobre a linguagem e os materiais utilizados para "animar" os EST}

71 Nos estudos abordados neste artigo observam-se a necessidade e o esforço dos profissionais "do conceito" em elaborarem materiais de formação coerentes e conectados ao máximo com a realidade sobre as quais intervêm. Trata-se, então, de um ponto que remete à relativa dificuldade e decisiva importância destes materiais para um bom encaminhamento dos EST e do processo de pesquisa como um todo e, mesmo, para além dele.

Nas pesquisas citadas, as linguagens utilizadas para tratar de conceitos teóricos, bem como para remeter às próprias formulações das trabalhadoras (como método de confrontação às próprias falas) procuraram ser mescladas.

Dessa forma, ao se falar de um determinado tema teórico como, por exemplo, competência profissional ou entidades coletivas relativamente pertinentes (Schwartz \& Durrive, 2010), na primeira pesquisa relatada, abordou-se o conceito acadêmico em conjunto com a apresentação (em papéis A4 colados na parede da sala onde ocorria o 
EST) de falas das próprias trabalhadoras - extraídas das visitas e/ou de Encontros anteriores - induzindo à discussão sobre a realidade vivida pelas participantes. Na segunda experiência também se operou de forma semelhante, porém a apresentação foi feita através do uso do computador.

Uma outra estratégia adotada na pesquisa de doutorado foi de abordar determinados problemas através de perguntas colocadas nos slides. Desta forma, buscou-se seguir os princípios ergológicos e dialógicos (Athayde et al, 2014) e a postura de humildade epistemológica (Schwartz \& Durrive, 2010) frente à complexidade da atividade, admitindo-se zonas de cultura e incultura entre as partes.

É importante destacar que não somente os materiais e tipos de linguagem utilizados pelo "animador" devem ser fortemente contextualizados e adequados ao coletivo participante (por exemplo, no que tange ao seu acesso e tradição na utilização do discurso formal), como também é importante entender que é muitas vezes ao longo do processo de realização dos EST que a construção destas linguagens vai se definindo ${ }^{[12]}$. Esta questão traz à tona, também, a importância de se manter a discussão ad hoc sobre o processo em andamento da pesquisa, de forma paralela à realização dos EST, ampliando a reflexão e auxiliando na recriação constante dos recursos utilizados nos encontros.

\subsection{O desafio de encaminhamentos efetivos e os riscos de insucesso}

76 A discussão sobre este ponto é, a nosso ver, crucial e talvez a mais importante. É necessário lembrar que, ao realizar uma pesquisa sobre o trabalho das pessoas, estamos, necessariamente, intervindo "na vida dos outros" (Schwartz, 2005) e isso é algo que requer grande prudência por parte dos profissionais de pesquisa e analistas do trabalho. Schwartz (idem) chama atenção para o fato de que é toda a vida das pessoas no trabalho que é implicada através de critérios visíveis ou invisíveis das escolhas feitas durante o desenvolvimento das atividades de trabalho. Por isso, os pesquisadores devem ser atentos e humildes (no sentido epistemológico) aos debates ocorridos entre os próprios trabalhadores antes mesmo de uma intervenção.

Esta observação contribui para refletir sobre os limites e as dificuldades enfrentadas pela equipe de pesquisa-intervenção no que tange às repercussões dos EST e os encaminhamentos que dele decorrem. Por não se tratar de um método objetivo/ quantitativo (justamente porque visa dar visibilidade ao que não é facilmente notável/ objetivável nas atividades de trabalho), apesar de ter como princípio a transformação das situações nocivas à saúde dos participantes, não há como oferecer garantias sobre tal transformação. Os riscos de insucesso existem e já foram problematizados por autores que discutem as intervenções baseadas na ergologia:

Se a vida dos outros está (...) sempre implicada, então, "a intervenção", no seu invólucro espaço-temporal, formalizado, visível, tem certamente sempre um aspecto pontual, insatisfatório, inadaptado, em relação aos problemas que ela encontra; ela está sempre em perigo de agir em parte às cegas, ao cortar certas dimensões da "vida dos outros" investidas na situação (Schwartz, 2005, p. 91, tradução livre).

A intervenção pretende fazer evoluir favoravelmente o equilíbrio ali presente, muitas vezes normopático, patogênico, mas nunca se terá garantia de que essa evolução ocorrerá. Pior, pode haver retaliações das partes envolvidas, ao se sentirem ameaçadas. Como vida e trabalho não se 
dissociam, uma mudança no trabalho pode trazer consequências duras para quem o vive. (Athayde et al, 2014, p. 12)

Frente a essa inevitável problemática que marca este tipo de pesquisa-intervenção, Athayde et al (2014) chamam a atenção para a importância da postura, sensibilidade e compromisso ético do pesquisador na gestão desses riscos, com vistas à manutenção do objetivo inicial da sua entrada no campo: a mudança positiva daquele meio de trabalho.

Assim, como um mediador, este profissional deve atuar para a garantia da visibilidade (e encaminhamento) do que é discutido e validado nos EST. Deve-se também ressaltar que o desejo e o comprometimento dos trabalhadores em participar dos EST parecemnos fundamentais para o bom andamento da intervenção e para que os encaminhamentos formulados pela CAPI possam ter força em serem pleiteados e conquistados de fato.

Soma-se a isso, sem dúvida, a necessária busca e conquista (nem sempre fácil), pelo pesquisador, do real engajamento também por parte das hierarquias com poder de decisão e encaminhamento de ações voltadas às transformações positivas no trabalho.

81 Ressaltamos, ainda, a importância da construção - necessariamente conjunta entre pesquisadores e protagonistas das atividades - de ferramentas de avaliação dos EST e monitoramento dos encaminhamentos e acordos definidos de forma coletiva. Avaliação que permita colocar à prova a própria ferramenta, visando à crítica e à reconstrução permanentes de seu uso. Monitoramento que contribua não somente para a conquista de mudanças no trabalho favoráveis à saúde, mas também para o estreitamento de relações entre a área da pesquisa acadêmica e as áreas de produção, no sentido da crescente viabilização de Comunidades Ampliadas de Pesquisa e Intervenção.

\subsection{Sobre o caráter formativo dos EST e sua importância para a conquista da saúde}

2 Nas duas experiências pudemos observar a potência dos EST em relação ao seu caráter formativo. Ficou visível para nós como os sujeitos, desde a primeira participação nos EST, foram construindo um novo olhar sobre as questões relacionadas à saúde e ao trabalho. As posturas, a participação e até mesmo a linguagem foram, pouco a pouco, se transformando, assim como as interações proporcionadas pelo DD3P instrumentalizaram os trabalhadores. Consequentemente, alcançou-se maior profundidade nas discussões, o que evidencia que a continuidade dos EST colabora de modo significativo para a produção de conhecimento, a formação e o desenvolvimento do coletivo.

Entendendo a reflexão e a análise coletiva no trabalho, sobre o trabalho, pelo trabalho e para o trabalho como parte fundamental da relação entre formação e trabalho, vê-se os EST como espaços privilegiados para a interlocução entre a realidade diária e concreta e o esforço pela sistematização e avanço nas discussões da técnica e do refinamento de conceitos, bem como da dimensão ética nos meios produtivos.

Assim, o debate sobre a formação no trabalho não caminharia na perspectiva de transformação-adaptação das pessoas às condições de trabalho dadas, mas sim para a transformação dos meios de trabalho pelas pessoas que trabalham. Este nos parece um aspecto fundamental e, neste sentido, almeja-se que tal caráter formativo dos EST possa 
promover, de forma indissociável, o desenvolvimento das pessoas em seu próprio curso e a ação sobre os elementos de trabalho (Lacomblez, Teiger \& Vasconcelos, 2014).

A respeito desta questão, Vasconcelos \& Lacomblez (2004) enfatizam, com base nas contribuições da Ergonomia da Atividade, da Psicologia do Trabalho e da Didática Profissional, a necessidade de que a formação para o trabalho ocorra de maneira fortemente contextualizada, onde a situação de trabalho apareceria como local privilegiado para a produção de conhecimentos (idem, p. 167).

Ressalta-se, assim, que os EST devem ser realizados em proximidade com situações de trabalho e feitos com grupos de pessoas que, de fato, configurem coletivos de trabalho. Neste sentido, devem ocorrer não necessariamente no próprio ambiente de trabalho, mas, ao menos, em um "local identificado com o trabalho" (Dejours, 2008, p. 109).

Nessa direção, a ideia de formação se aproxima muito da perspectiva de uma (trans)formação do trabalho. Este eixo, portanto, atuaria com grande força na própria concepção de uma organização aprendente (Zarifian, 2003), que se caracterizaria por utilizar seus próprios recursos (especialmente os chamados "eventos", situações atípicas ocorridas) como fonte de aprendizagem e formação contínua de seus integrantes.

88 Assim, a importância epistemológica da circulação de um diálogo na perspectiva de um DD3P é, sem dúvida, uma grande preocupação ao se utilizar os EST. No entanto, conforme salienta Nouroudine (2002), a manifestação de um processo dialógico efetivo pressupõe que o saber ou o conteúdo dos enunciados circulem nos dois sentidos entre os interlocutores. E isso, segundo o autor, possui valor epistemológico apenas se não houver, a priori, invalidação do conteúdo dos enunciados de uma das categorias de locutores (protagonistas do trabalho ou pesquisadores do trabalho), de modo que no processo dialógico a instrução seja, de fato, recíproca.

Neste sentido, a riqueza do DD3P seria justamente a possibilidade de inscrever pesquisadores e protagonistas do trabalho em intercâmbios e confrontações que conduzam à produção mútua de conhecimentos sobre o trabalho, levando a se considerar o conhecimento das atividades humanas não como um estado a ser atingido ou produzido, mas como um processo a ser acionado e nunca inteiramente acabado (Idem, ibidem).

90 É necessário, ainda, ressaltar a luta permanente pela saúde nos meios de trabalho como aspecto fundamental e transversal ao debate metodológico a respeito dos EST. Numa perspectiva canguilheniana, Brito (2004) afirma que "a promoção da saúde nesses ambientes deveria partir das normas daqueles que trabalham e das formas de que eles lançam mão para gerir essas infidelidades" (p. 109), ou seja, uma promoção da saúde que considera que a busca por um ambiente de trabalho saudável faz parte da própria atividade.

91 Como proposto por Silva, Brito, Neves e Athayde (2009), trata-se de um deslocamento na direção de uma proposta de Promoção da Saúde a partir das Situações de Trabalho considerando seu caráter situado, os recursos sociais e pessoais, o desenvolvimento da experiência (Clot, 2006) e a busca da expansão do poder de agir dos trabalhadores (Clot, 2008).

92 Neste sentido, de acordo com Schwartz (2000), a reconciliação entre o trabalho e a vida é obtida pela possibilidade de criação, por parte dos trabalhadores, de "micronormas" no meio de trabalho. Assim, os EST devem ser dirigidos no sentido de produzirem as 
condições para a ampliação da capacidade dos trabalhadores de criarem novas normas de vida e trabalho, tendo em vista as singularidades das situações.

É, portanto, na perspectiva de construção e expansão de espaços coletivos que favoreçam as renormatizações e a ampliação da margem de segurança dos trabalhadores sobre a sua saúde que entendemos que a realização dos EST pode contribuir para a conquista de um trabalho promotor de saúde.

\section{BIBLIOGRAFIA}

Athayde, M., Zambroni-de-Souza, P. \& Brito, J. (2014). Intervenção e pesquisa em psicologia: uma postura ergológica. In P. B. Bendassoli \& L. A. Soboll (Orgs.), Métodos de Pesquisa e Intervenção em Psicologia do Trabalho: Clínicas do Trabalho (pp.129-158). São Paulo: Atlas.

Barros-Duarte, C., Cunha, L., \& Lacomblez, M. (2007). INSAT - uma proposta metodológica para análise dos efeitos das condições de trabalho sobre a saúde. Laboreal, 3, 2, 54-62. Retirado julho, 15, 2013 de: http://laboreal.up.pt/media/artigos/146/54_62pt.pdf

Brito, J. (2004). Saúde do trabalhador: reflexões a partir da abordagem ergológica. In M. Figueiredo, M. Athayde, J. Brito \& D. Alvarez (Orgs.), Labirintos do trabalho: interrogações e olhares sobre o trabalho vivo (pp. 91-114). Rio de Janeiro: DP\&A.

Canguilhem, G. (1990/ 2011). O normal e o patológico (7 $7^{\mathrm{a}}$ ed. rev.; Maria Thereza R. C. Barrocas, Trad.). Rio de Janeiro: Ed. Forense Universitária.

Clot, Y . (2006). A função psicológica do trabalho (Adail Sobral, Trad.). Petrópolis: Vozes.

Clot, Y. (2008). Travail et pouvoir d'agir. Paris: PUF.

Dejours, C. (1986). Por um novo conceito de saúde. Revista Brasileira de Saúde Ocupacional, 14, 54, 7-11.

Dejours, C. (2008). A metodologia em psicopatologia do trabalho. In S. Lancman \& L.I. Snelwar (Orgs.), Christophe Dejours: da psicopatologia à psicodinâmica do trabalho (pp.107-128) (2a ed. rev.ampl.; Franck Soudant, Trad.). Rio de Janeiro: Editora Fiocruz; Brasília: Paralelo 15.

Durrive, L. (2010). Anexo ao capítulo 11: Pistas para o ergoformador animar os encontros sobre o trabalho. In Y. Schwartz \& L. Durrive (Orgs.), Trabalho e Ergologia: conversas sobre a atividade humana (pp. 309-318), (2ª ed.; Jussara Brito \& al. Trad). Niterói: Eduff.

França, M. B., Di Fanti, M. G. C. \& Vieira, M. A. M. (2005). Análise dialógica da atividade profissional: contribuições teórico-metodológicas para os estudos sobre linguagem/ trabalho. In D. Faita (Org.), Análise dialógica da atividade profissional (pp. 7-12). Rio de Janeiro: Imprinta.

Freire, P. (1970/ 2011). Pedagogia do oprimido (50ª ed.). Rio de Janeiro: Paz e Terra.

Gomes, L. (2011). Trabalhar em UTI Neonatal: os desafios da relação de serviço e a saúde das/os técnicas/ os de enfermagem. Tese de Doutoramento em Saúde Pública, Escola Nacional de Saúde Pública Sérgio Arouca da Fundação Oswaldo Cruz, Rio de Janeiro. 
Guérin, F., Laville, A., Daniellou,F., Duraffourg,J. \& Kerguelen, A. (2001). Compreender o trabalho para transformá-lo: a prática da ergonomia (Giliane M.J. Ingratta \& Marcos Maffei, Trad.). São Paulo: Editora Edgard Blücher.

Hirata, H. (2002). Nova divisão sexual do trabalho? Um olhar voltado para a empresa e a sociedade. São Paulo: Boitempo Editorial.

Hubault, F. (2009). L'approche ergonomique des questions santé / travail. Mouvements, 2(58), 98-102. Retirado julho, 9, 2013 de: http://www.cairn.info/article.php? ID_REVUE=MOUV\&ID_NUMPUBLIE=MOUV_058\&ID_ARTICLE=MOUV_058_0097

Kergoat, D. (1989). Da divisão do trabalho entre os sexos. In H. Hirata (Org.), Divisão capitalista do trabalho, Tempo Social, 1, 2, 88-96.

Kergoat, D. (1996). Relações sociais de sexo e divisão sexual do trabalho. In M. J., D. Meyer \& V. Waldow (Orgs.), Gênero e saúde (pp.19-28). Porto Alegre: Artes Médicas.

Lacomblez, M., Teiger, C. \& Vasconcelos, R. (2014). A ergonomia e o "paradigma da formação dos atores": Uma parceria formadora com os protagonistas do trabalho. In P. F. Bendassolli \& L. A. Soboll (Orgs.), Métodos de Pesquisa e Intervenção em Psicologia do Trabalho (pp. 159-183). São Paulo: Editora Atlas.

Lhuilier, D. (2006). Cliniques du travail. Toulouse: Érès.

Masson, L. (2007). A dimensão relacional do trabalho de auxiliares de Enfermagem de uma Unidade Neonatal: uma análise do ponto de vista da atividade. Dissertação de Mestrado em Saúde Pública, Escola Nacional de Saúde Pública Sérgio Arouca da Fundação Oswaldo Cruz, Rio de Janeiro.

Nouroudine, A. (2002). A linguagem: dispositivo revelador da complexidade do trabalho. In M. C. Souza-e-Silva \& D. Faita (Orgs.), Linguagem e Trabalho: construção de objetos de análise no Brasil e na França (pp.17-30) (Ines Polegatto \& Décio Rocha Trad.). São Paulo: Cortez.

Schwartz,Y. (2000). Le paradigme ergologique ou un métier de philosophe. Toulouse: Octares.

Schwartz,Y. (2005). Intervenir dans la vie des autres. Calidoscópio, 3, 2, 88-96.

Schwartz Y. (2010a) Trabalho e uso de si. In Y. Schwartz \& L. Durrive (Orgs.), Trabalho e ergologia: conversas sobre a atividade humana (pp. 191-206) (2 $2^{\underline{a}}$ ed.; Jussara Brito \& al. Trad). Niterói: Eduff.

Schwartz Y. (2010b) A dimensão coletiva do trabalho: as "ECRP". In Y. Schwartz\& L. Durrive (Orgs.), Trabalho e ergologia: conversas sobre a atividade humana (pp. 151-166) (2 ${ }^{\mathrm{a}}$ ed.; Jussara Brito \& al. Trad). Niterói: Eduff.

Schwartz, Y., \& Durrive, L. (2010). Trabalho \& Ergologia: Conversas sobre a atividade humana. (Y. Schwartz \& L. Durrive, Orgs.) (2 ${ }^{\text {a }}$ ed.; Jussara Brito \& al. Trad). Niterói: Eduff.

Silva, E. F., Brito, J., Neves, M. Y. \& Athayde, M. (2009). A promoção da saúde a partir das situações de trabalho: considerações referenciadas em uma experiência com trabalhadores de escolas públicas. Interface (Botucatu), 13, 30, Retirado abril, 4, 2014 de: http://www.scielo.br/scielo.php? script=sci_arttext\&pid=S1414-32832009000300010\&lng=en\&nrm=iso

Tertre, C. du. (2005). Services immatériels et relationnels : intensité du travail et santé. @ctivités, 2(1), 37-49. Retirado junho, 3, 2013 de: http://www.activites.org/v2n1/dutertre.pdf

Vasconcelos, R., Lacomblez, M.(2004). Entre a auto-análise do trabalho e o trabalho de autoanálise: desenvolvimento para a psicologia do trabalho a partir da promoção da segurança e saúde no trabalho. In M. Figueiredo, M. Athayde, J. Brito \& D. Alvarez (Orgs.), Labirintos do trabalho: interrogações e olhares sobre o trabalho vivo (pp. 161-187). Rio de Janeiro: DP\&A. 
Vidal, M. C. (2003). Guia para análise ergonômica do trabalho na empresa: uma metodologia realista, ordenada e sistemática. Rio de Janeiro: Editora Virtual Científica.

Zarifian, P. (2001a) Objetivo competência: por uma nova lógica ( $M^{a}$ Helena C.V. Trylinski Trad.). São Paulo: Atlas.

Zarifian, P.(2001b). Mutação dos sistemas produtivos e competências profissionais: a produção industrial de serviço. In M. S. Salerno (Ed.), Relação de serviço: Produção e avaliação (pp. 67-94). São Paulo: SENAC São Paulo.

Zarifian, P.(2001c). Valor, organização e competência na produção de serviço: esboço de um modelo de produção de serviço. In M. S. Salerno (Ed.), Relação de serviço: Produção e avaliação (pp. 95-150). São Paulo: SENAC São Paulo.

Zarifian, P. (2003). Organisation apprenante et formes de l'expérience (pp.93-104). In P. Zarifian, A quoi sert le travail? Paris: La dispute.

\section{NOTAS}

1. Como meio de resumir e evitar a repetição excessiva da expressão "Encontros sobre o trabalho", e entendendo-a como expoente de um dispositivo grupal diferenciado, por vezes a substituiremos por EST.

2. Conforme Brito (2011), de forma geral, tais limites estão ligados às mudanças no contexto histórico em que a experiência italiana se desenvolveu. Um de seus problemas seria o de transmitir a ideia de que o conhecimento sobre a atividade de trabalho pertence ao domínio científico no sentido clássico. Outra questão se refere à pouca visibilidade dada pelas CCA ao terceiro polo do dispositivo trazido à discussão por Schwartz, o que ao longo da experiência italiana era "suprido" pela consciência de classe e a dinâmica sindical de então (Brito, idem).

3. Comunidade Ampliada de Pesquisa (CAP) é a denominação sugerida por Jussara Brito, Milton Athayde e Mary Neves (2003) ao tipo de relação, de encontro, de confronto, de diálogo crítico entre o polo dos saberes presentes nas disciplinas científicas e o polo dos saberes colocados em prática e desenvolvidos no cotidiano de trabalho, cuja inspiração veio do Movimento Operário Italiano de luta pela saúde (MOI) (uma das principais referências para a constituição da perspectiva ergológica). Em texto mais recente (Athayde, Brito e Zambroni, 2014), foi proposta uma atualização deste termo para Comunidade Ampliada de Pesquisa e Intervenção (CAPI).

4. França et al (2005) chamam a atenção para a importância de não somente compreender o trabalho para transformá-lo (regra de ouro da Ergonomia da Atividade), mas também de se transformar o trabalho para compreendê-lo.

5. Unidade composta pelos seguintes setores, no caso da instituição estudada : Unidade de Tratamento Intensivo Neonatal (UTI Neonatal), Unidade Intermediária (UI) e Unidade de Baixo Risco (UBR ou Berçário).

6. Em conjunto com uma análise documental (legislação, rotina descrita das auxiliares de enfermagem, a planta física da UTI Neonatal, um relatório sobre dimensionamento de pessoal na unidade) e a realização de conversas com a chefia de enfermagem da UTI Neonatal.

7. Esse levantamento foi feito a partir de um cartaz-convite, afixado num quadro de avisos da copa da Unidade Neonatal, com um espaço a ser preenchido pelas auxiliares.

8. Estes novos Encontros de (in)validação seguiram a mesma dinâmica metodológica dos primeiros EST, com a diferença da utilização do material impresso e também fizeram parte de uma tese de Doutorado (Masson, 2012), que teve como foco o tema da formação e trabalho.

9. Construído em seu conteúdo e produzido graficamente pela nova equipe de pesquisa que incorporava nesta etapa mais uma das autoras deste artigo : Luciana Gomes. 
10. Insats - Trata-se da adaptação, para as atividades de serviço no Brasil, do Inquérito de Saúde e Trabalho (Insat), realizada por Jussara Cruz de Brito, Luciana Gomes e Simone Oliveira, da Escola Nacional de Saúde Pública da Fundação Oswaldo Cruz. Tendo a colaboração, na versão de 2009, de Ana Maria Ramos Zambroni de Souza e Filipe Guterres. O Insat foi elaborado em 2007 por : Carla Barros-Duarte, Liliana Cunha e Marianne Lacomblez do Centro de Psicologia da Universidade do Porto/Portugal (Unidade de Investigação da Fundação para Ciência e Tecnologia). Esse questionário foi desenvolvido com o intuito de conhecer melhor os fatores que interferem nas várias dimensões da saúde de forma a contemplar problemas e doenças provocados pelas condições de trabalho para além das doenças profissionais reconhecidas. As questões foram construídas na tentativa de despertar nos trabalhadores uma consciência sobre os efeitos das condições em que estão trabalhando (Barros-Duarte et al, 2007). Para mais informações sobre este instrumento de investigação, ver o artigo : Barros-Duarte C, Cunha L, Lacomblez M.INSAT - Uma proposta metodológica para análise dos efeitos das condições de trabalho sobre a saúde. Rev. Laboreal [Internet]. 2007.3 (2) : 54-62. Disponível em : http:// laboreal.up.pt/revista/artigo.php?id=37t45nSU547112311:499682571

11. Na pesquisa de mestrado realizada por Ana Maria Zambroni de Souza (2010), utilizou-se estratégia metodológica semelhante, isto é, a confrontação de dados produzidos durante as Visitas à UTI neonatal e os recolhidos através do INSATS, mas sem fazer uso do Dispositivo EST. Essa pesquisa foi desenvolvida em um Hospital Universitário do Estado da Paraíba.

12. Como salientam Athayde et al (2014), esta seria especialmente uma realidade brasileira. $\mathrm{Na}$ França, onde a perspectiva ergológica tem sua origem, houve a construção por pesquisadores de um material educativo ("maleta pedagógica"), com conteúdos mais gerais, que é utilizada em situações de pesquisa-intervenção diversas. Nas experiências brasileiras, segundo os autores, "em geral os profissionais de pesquisa e/ou intervenção, a partir do patrimônio já existente sobre a temática, vão preparando material de discussão à medida que os Encontros avançam" (idem, ibidem).

\section{RESUMOS}

Buscamos discutir o uso de uma ferramenta metodológica, denominada "Encontros sobre o Trabalho", que segue os princípios da Ergologia, visando propiciar o debate, a reflexão e o desenvolvimento da atividade de trabalho. A discussão é realizada a partir da apresentação de suas formas de uso em duas experiências de pesquisa que procuraram compreender-transformar a relação saúde-trabalho de profissionais de enfermagem em Unidades de Tratamento Intensivo Neonatais. Constatamos que esse dispositivo grupal apresenta um grande potencial para a transformação positiva no pensar-agir dos protagonistas do polo da atividade e do polo dos saberes formais, assim como nos meios do trabalho. Identificamos desafios e aprendizagens em sua operacionalização, referentes, especialmente, à linguagem e aos materiais utilizados para animar os Encontros, aos encaminhamentos efetivos e riscos de insucesso, ao seu caráter formativo e à sua importância para a conquista da saúde.

Este artículo discute el uso de una herramienta metodológica, denominada "Encuentros sobre el Trabajo", que basada en los principios de la Ergología, con la finalidad de propiciar el debate, la reflexión y el desarrollo de la actividad de trabajo. La discusión se desarrolla a partir de la presentación de las formas de uso de esta herramienta en dos experiencias de investigación, que 
buscaron comprender y transformar la relación "salud-trabajo" de profesionales de enfermería en Unidades de Cuidados Intensivos en Neonatología. Constatamos que este dispositivo grupal presenta una gran ventaja para la transformación positiva en el pensar-actuar de los protagonistas en el ámbito de la actividad de los saberes formales, así como en el de los medios de trabajo Identificamos desafíos y aprendizajes durante la operacionalización de la herramienta referidos al lenguaje y a los materiales utilizados para animar los Encuentros, a las acciones efectivas y a los riesgos de fracaso, así como a su carácter formativo y a su importancia en la conquista de la salud.

Nous chercherons ici à débattre de l'utilisation d'un outil méthodologique, dénommé « Rencontres sur le Travail », qui suit les principes de l'Ergologie, afin de susciter la réflexion sur l'activité de travail et son développement. La discussion est développée à partir de la présentation des formes d'utilisation de cet outil dans deux expériences de recherche, en vue de comprendre-transformer la relation santé-travail de professionnels des soins infirmiers en Unités de Soins Intensifs Néonataux. Nous constatons que ce dispositif groupal présente un grand potentiel pour la transformation positive au niveau du penser-agir des protagonistes du pôle d'activité et du pôle de savoirs formels, ainsi que dans les milieux de travail. Nous identifions les défis et les apprentissages de la mise en place de l'outil, concernant notamment : le langage et les matériels utilisés pour animer les Rencontres, les acheminements effectifs et les risques d'échec, son caractère formatif et son importance pour la conquête de la santé.

We intend to discuss the use of a methodological tool, called "Meetings about the work", which follows the principles of Ergology, in order to promote the discussion, the reflection and the development of the work activity. The discussion is developed from the presentation of the ways this tool is used in two research experiences that sought to understand-transform the relation between health and work of nurses in NICU. We found that this group device has great potential for positive transformation in the thinking-acting of key players from the activity group and from the formal knowledge group, as well as in the labour means. We have identified challenges and lessons learned in its operation relating, specially, to the language and the materials used to animate the Meetings, the effective referrals and risks of failure, to its educational character and to its importance for the achievement of health.

\section{ÍNDICE}

Palavras-chave: encontros sobre o trabalho, ergologia, UTI Neonatal, auxiliares e técnicos de enfermagem, saúde do trabalhador

Palabras claves: encuentros sobre el trabajo, ergología, UCI de neonatología, auxiliares y técnicos en enfermería, salud del trabajador

Mots-clés: rencontres sur le travail; ergologie, USI néonatale, aides et techniciens en soins infirmiers, santé du travailleur

Keywords: Meetings about the work, ergology, Neonatal Intensive Care Units, nurses, occupational health

\section{AUTORES}

\section{LETÍCIA PESSOA MASSON}

Centro de Estudos da Saúde do Trabalhador e Ecologia Humana (CESTEH), Escola Nacional de Saúde Pública (ENSP), Fundação Oswaldo Cruz (FIOCRUZ), Rua Leopoldo Bulhões, 1480, sala 302, 
Manguinhos - Rio de Janeiro - RJ. Brasil, CEP: 21041-210

leticiamasson@ensp.fiocruz.br

\section{LUCIANA GOMES}

Centro de Estudos da Saúde do Trabalhador e Ecologia Humana (CESTEH), Escola Nacional de Saúde Pública Sérgio Arouca (ENSP), Fundação Oswaldo Cruz (FIOCRUZ), Rua Leopoldo Bulhões 1480 - Manguinhos - Rio de Janeiro - RJ, Brasil, CEP: 21041-210

lucianagomes@ensp.fiocruz.br

\section{JUSSARA BRITO}

Grupo de Pesquisa e Intervenção em Atividade de Trabalho, Saúde e Relações de Gênero, Escola Nacional de Saúde Pública Sergio Arouca (ENSP), Fundação Oswaldo Cruz (FIOCRUZ),

Pesquisadora do CNPq, Rua Leopoldo Bulhões, 1480, Manguinhos - Rio de Janeiro - RJ. Brasil, CEP: 21041-210

jussara@ensp.fiocruz.br 